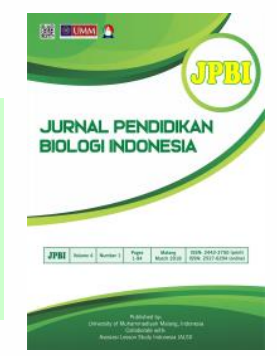

Research Article

\title{
Cladogram misreading of undergraduate students in understanding evolutionary
}

Sa'diatul Fuadiyah a,1,*, Topik Hidayat b,2, Didik Priyandoko b,3

a Department of Biology Education, Universitas Negeri Padang, Jl. Prof. Dr. Hamka, Padang City, West Sumatra 25171, Indonesia

b Department of Biology Education, School of Post Graduates, Universitas Pendidikan Indonesia, Jl. Dr. Setiabudi No.229, Bandung, West Java, 40154, Indonesia

sadiyah@fmipa.unp.ac.id *; 2 topikhidayat@upi.edu, ${ }^{3}$ didikpriyandoko@upi.edu

* Corresponding author

\begin{tabular}{|c|c|}
\hline ARTICLE INFO & ABSTRACT \\
\hline \multirow[t]{2}{*}{$\begin{array}{l}\text { Article history } \\
\text { Received: } 01 \text { June } 2020 \\
\text { Revised: } 07 \text { June } 2021 \\
\text { Accepted: } 17 \text { July } 2021 \\
\text { Published: } 31 \text { July } 2021 \\
\text { Keywords } \\
\text { Cladogram } \\
\text { Evolutionary } \\
\text { Misreading } \\
\text { Undergraduate students }\end{array}$} & $\begin{array}{l}\text { The student's ability to understand evolutionary studies is determined by representing a } \\
\text { phylogenetic tree or cladogram. This study aims to determine the tree thinking ability, } \\
\text { especially the students' reading ability in interpreting the cladogram. This descriptive } \\
\text { study involved } 29 \text { students as subjects. Students are selected by purposive random } \\
\text { sampling, only students who have attended and studied evolution courses. The data } \\
\text { collection instrument used tests and interview guidelines. The test questions consist of } \\
20 \text { multiple choice questions with five answer choices. The difficulty level of the } \\
\text { questions used includes understanding, applying, analyzing, and evaluating. The } \\
\text { phylogenetic tree interpretation refers to four indicators, including the most recent } \\
\text { common ancestor (MRCA), monophyletic group, branch proximity, contemporary } \\
\text { descendant, and counting the branch or nodes position. The data obtained were } \\
\text { analyzed using Microsoft Excel } 2013 \text { and Anates-V4, then presented in percentage } \\
\text { form. The results showed that many students misinterpreted the cladogram. } \\
\text { Furthermore, errors in cladogram interpretation occurred in monophyletic group } \\
\text { indicators (38\%), most common ancestor (59\%), branch proximity (41\%), contemporary } \\
\text { ancestry (39\%), and branch position calculations (53\%). These results indicate that } \\
\text { misreading of analysis in cladogram interpretation is moderate to high, so it is } \\
\text { necessary to formulate the most appropriate way to teach phylogenetic studies in } \\
\text { evolution. }\end{array}$ \\
\hline & $\begin{array}{l}\text { Copyright } \odot 2021, \text { Fuadiyah et al } \\
\text { This is an open access article under the CC-BY-SA license }\end{array}$ \\
\hline $\begin{array}{l}\text { How to cite: Fuac } \\
\text { underst } \\
\text { jpbi.v7i2 }\end{array}$ & $\begin{array}{l}\text { T., \& Priyandoko, D. (2021). Cladogram misreading of undergraduate students } \\
\text { JPBI (Jurnal Pendidikan Biologi Indonesia), } 7 \text { (2), 179-187. doi: https://doi.org/10.22219 }\end{array}$ \\
\hline
\end{tabular}

\section{INTRODUCTION}

Evolution is one of the core studies in biology majors at universities, biology science, and biology education (Hiatt et al., 2013; Novick \& Catley, 2018; Saputra, 2017). The study of evolution is called the unifying science of biology and helps understand how the kinship of living things occurs (Klucevsek \& Brungard, 2016; Meisel, 2010). However, the results showed that most biology students had difficulty understanding the core concepts in evolution, including the phylogenetic studies (Baum et al., 2005; Dunk et al., 2019; Meir et al., 2007; Phillips et al., 2012). Furthermore, Hidayat and Pancoro (2016) shows that the 
attention of biology students to taxonomy and evolution courses is low. Students assume that the two materials are theoretical and boring, so a solution is needed to overcome the lack of mastery of these concepts (Gregory, 2008; Mattsson \& Mutvei, 2015).

One solution that can be used is strengthening phylogenetic concepts and tree thinking in learning (Bokor et al., 2014; McCullough et al., 2020). This study links the concept of evolution with several approaches and concepts of biological sciences such as biodiversity, taxonomy, biosystematics, morphology, anatomy, and others (Dees et al., 2014; Halverson et al., 2011; Whitfield, 2012). Phylogenetic bases and tree thinking are often minimized or even excluded in learning, even though they can help students master the concept of evolution (Bokor et al., 2014). The findings of some research reveal that students' low mastery of the concept of evolution is due to the availability of textbooks that have not been used to accommodate the learning needs of phylogenetic bases and tree thinking concepts (Padian, 2008; Saputra, 2017). Tree thinking is needed to develop mastery of the concept of evolution and knowledge of biodiversity (Baum et al., 2005; Morrison, 2012). Tree thinking skills identified can help students interpret the evolutionary history and phylogenetic trees (Gregory, 2008).

The concept of tree thinking is closely related to the ability to read, interpret (Halverson, 2011), and understand information about evolutionary relationships (Novick et al., 2012), patterns (Gibson \& Cooper, 2017), and processes associated with phylogenetic trees (Phillips et al., 2012; Schramm et al., 2021). Thus, students' ability to interpret and recognize patterns when manipulating or creating phylogenetic trees is essential. Meisel revealed that tree-thinking skills are priorities in improving the biology curriculum (Meisel, 2010). However, some researchers also stated that tree thinking is a skill that is difficult for students to use, and misconceptions often occur, making it difficult to interpret correctly (Halverson et al., 2011; Kummer et al., 2016a).

Furthermore, students have difficulty interpreting the meaning and understanding of the hypotheses shown from them. Previous studies did not explicitly explain how students' thinking skills on the concept of evolution precisely. This study aims to determine the tree thinking ability of students in interpreting the cladogram of living things. This research can provide educators with an idea of using tree thinking as a solution when teaching phylogenetic trees to improve understanding of evolution.

\section{METHOD}

This descriptive research was conducted in December 2017. The subjects in this study were students of the Biology Education Study Program at a private university in West Java. The sampling technique used was purposive random as many as 29 students. Only students who have enrolled and studied evolutionary courses are involved in this research.

Collecting data using an objective test in the form of 20 multiple choice questions with five choices modified from Baum et al. (2005). Misreading analysis is part of a thought tree that looks at their ability to read and interpret cladogram. This ability is captured by using multiple-choice questions according to levels C2-C5 (understanding, applying, analyzing, and evaluating) in Bloom's revised taxonomy. Each question has its indicators which will be grouped into indicators (Dees et al., 2014), namely most recent common ancestor (MRCA), monophyletic group, branch proximity, contemporary descent, and calculating branch or node positions. The student's answer scores are used as analysis material to describe reading skills and any errors that occur when students read and interpret the cladogram. The correct answers for each question will be analyzed using Microsoft Excel 2013 and Anates-V4, and the percentage for each indicator can be seen in Table 1.

Table 1. Criteria of misreading's score

\begin{tabular}{cc}
\hline Category & Range of score (\%) \\
\hline Very low misreading & $81-100$ \\
Low misreading & $61-80$ \\
Moderate misreading & $41-60$ \\
High misreading & $21-40$ \\
Very high misreading & $0-20$ \\
\hline
\end{tabular}

Interviews were used as a secondary data collection method to analyze the factors causing the students' low ability to interpret cladogram and students' mastery of concepts in evolutionary learning. The interview 
topics asked included references in teaching courses, learning strategies/methods, and difficulties in studying evolution. The interview topic which was asked to the students was related to the students' learning achievement and mastery of concepts in the evolutionary learning about phylogenetic trees.

\section{RESULTS AND DISCUSSION}

The results showed that students had difficulty in interpreting the cladogram, resulting in misreading. Misreading on two of the five indicators is high, namely monophyletic group and contemporary descent at $38 \%$ and $39 \%$, respectively (Figure 1). Meanwhile, misreading on the branch proximity indicator is moderate $(41 \%)$. However, the scores on the three indicators differ very slightly. Meanwhile, misreading on the most recent common ancestor indicator and counting branch position was moderate with a score of $>50 \%$.

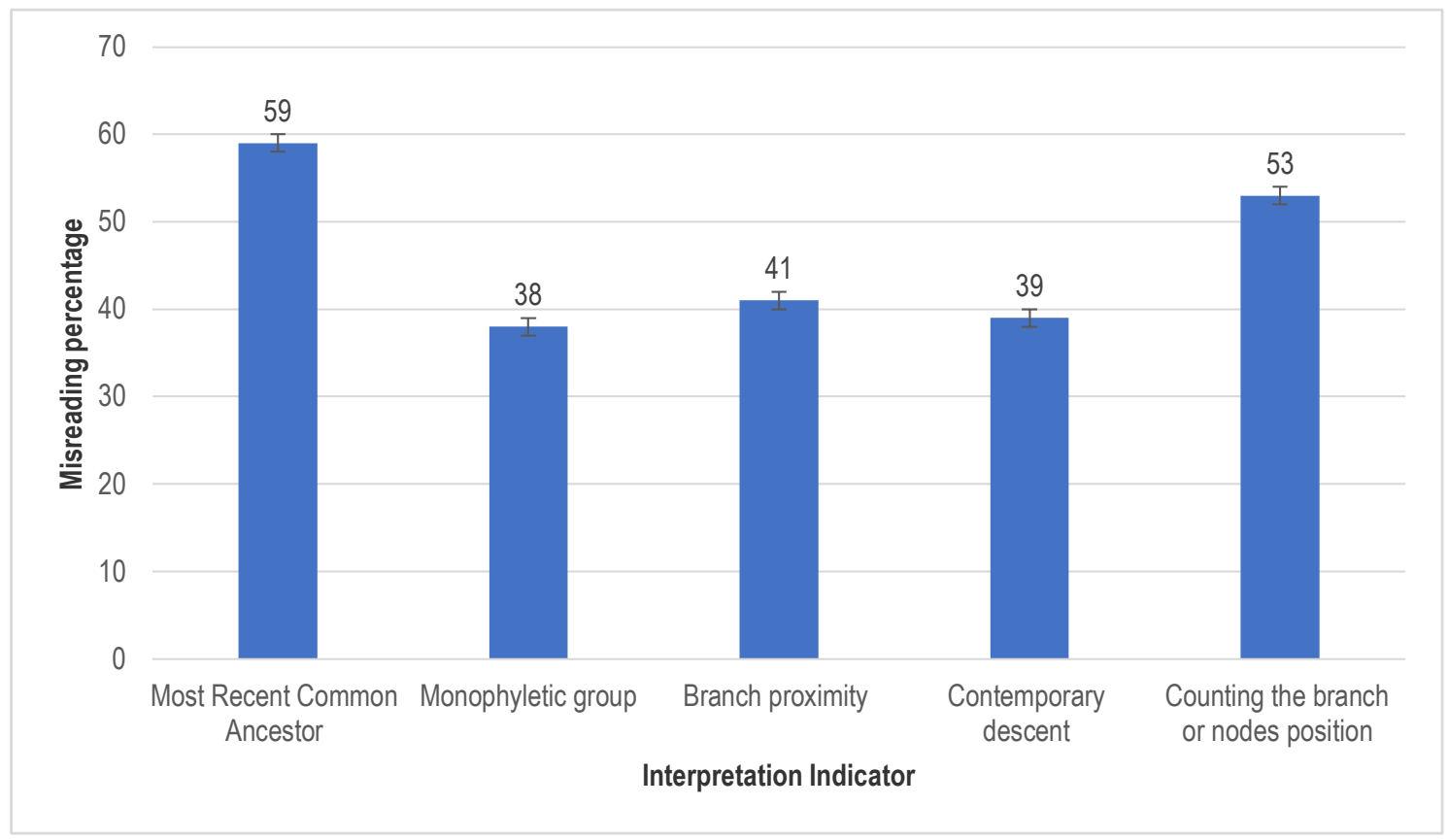

Figure 1. The percentage of undergraduate students' interpretation phylogenetic tree

Interpretation is one of skill in tree thinking. Interpretation is an explanation or answer those results from interpreting something. Misinterpretation occurs due to errors in reading. By doing this research, errors in reading the cladogram which result in misinterpretation of the cladogram will be seen. Based on Figure 1, undergraduate students' ability in interpreting cladogram is low because of misreading. Misinterpretation caused by inaccurate reading. Students have difficulties in monophyletic group with high misreading about $38 \%$ and moderate misreading on indicator most recent common ancestor about $59 \%$. Table 2 will show details of each indicator from each question that have been grouped into interpretation skill modified from Dees et al (2014) to know where misreading happened.

Table 2.The percentage comprehension student's ability to answer the questions that have suitable with interpretation indicator modified from Dees et al (2014).

\begin{tabular}{llcc}
\hline \multicolumn{1}{c}{ Interpretation indicator } & \multicolumn{1}{c}{ Question indicator } & Percentage (\%) & Categorized \\
\hline a. Most Recent Common & $\begin{array}{l}\text { 1. Concluding the synapomorphy } \\
\text { Ancestor (MRCA) }\end{array}$ & 69 & Low misreading \\
& $\begin{array}{l}\text { 2. Evaluating relatedness taxon with } \\
\text { different MRCA }\end{array}$ & 41 & Moderate misreading \\
& $\begin{array}{l}\text { 3. Using evidence from MRCA to } \\
\text { concluding synapomorphy character } \\
\text { 4. Determining position of MRCA } \\
\text { 5. Determining taxon descendant from } \\
\text { MRCA }\end{array}$ & 48.25 & Moderate misreading \\
& $\begin{array}{l}\text { 1. Determining sister group } \\
\text { 2. Evaluating relatedness by showing the } \\
\text { different form of cladogram }\end{array}$ & 63.5 & Very low misreading \\
\hline b. Monophyletic group & & 0 & Low misreading \\
\hline
\end{tabular}




\begin{tabular}{|c|c|c|c|}
\hline Interpretation indicator & Question indicator & Percentage (\%) & Categorized \\
\hline & 3. Determining name of taxon group & 41 & Moderate misreading \\
\hline \multirow[t]{4}{*}{ c. Branch proximity } & \multirow{4}{*}{$\begin{array}{l}\text { 1. Determining primitive taxon } \\
\text { 2. Determining outgroup } \\
\text { 3. Determining last recent taxon } \\
\text { 4. Determining taxon relatedness-based } \\
\text { branch proximity }\end{array}$} & 48 & Moderate misreading \\
\hline & & 90 & Very low misreading \\
\hline & & 66 & Low misreading \\
\hline & & 14.8 & Very high misreading \\
\hline \multirow[t]{3}{*}{ d. Contemporary descendant } & $\begin{array}{l}\text { 1. Determining combination character } \\
\text { number }\end{array}$ & 45 & Moderate misreading \\
\hline & $\begin{array}{l}\text { 2. Concluding character taxon from } \\
\text { character descendant in cladogram }\end{array}$ & 59 & Moderate misreading \\
\hline & $\begin{array}{l}\text { 3. Concluding a new species character } \\
\text { from character descendant in cladogram }\end{array}$ & 14 & Very high misreading \\
\hline \multirow[t]{2}{*}{$\begin{array}{l}\text { e. Counting the branch or } \\
\text { nodes position }\end{array}$} & 1. Counting number of clades & 38 & High misreading \\
\hline & 2. Placing taxon in node correctly & 69 & Low misreading \\
\hline
\end{tabular}

Table 2 shows the percentage of correct student answers, that there is a difference in the level of misreading that students get from each sub-indicator in multiple choice questions. In the research that has been done regarding the ability of students to read cladograms, it was obtained misreading data which was developed from the interpretation indicators (Dees et al., 2014). Interpretation is an explanation or answer to the result of interpreting something. Misinterpretation occurs because of an error in reading. By carrying out this research, errors in reading the cladogram that result in misinterpretation of the cladogram will be seen. Based on the average results of students' interpretation questions, it was obtained $46 \%$ with the moderate misreading category, meaning that the interpretation ability was also moderate. The following is an explanation of each indicator and sub-indicator of the instrument for interpretation.

\section{Most Recent Common Ancestor (MRCA)}

Most recent common ancestor is used to interpret taxa relatedness. Using most recent common ancestor by biologists in terms can understood about taxa relatedness or similarity to family trees of humans (Baum et al., 2005). The first interpretation indicator regarding common ancestry is divided into four sub-indicators of questions. Very low misreading occurred in the sub-indicator of determining the position of ancestors, which showed that many students answered correctly on the sub-indicator of the question. The second subindicator, determining kinship based on ancestry, obtained a percentage of $41 \%$ with a moderate misreading category. This shows that some students answered the questions correctly and used their mastery of concepts well. Based on Table 2, Most Recent Common Ancestor (MRCA) indicators are developed into the synapomorphy character, evaluating relatedness taxon with different MRCA, using evidence from MRCA to concluding synapomorphy character, determining position of MRCA, and determining taxon descendant from MRCA. Using evidence from MRCA to concluding synapomorphy character has high misreading percentage $(34.5 \%)$. Understanding about most recent common ancestor is key to interpret which characters have been passed on from common ancestors. Without the ability to interpret, students can't make inferences about the evolution of these characters and taxa, and makes them become uninformative (Kummer et al., 2016b). Another fact found in student interviews showed that only 2 students out of 8 student respondents could correctly define the meaning of common ancestor. This is one of the causes of the low ability of students to interpret common ancestry and questions based on indicators of common ancestry. The ability to determine the most recent ancestor is the key to interpreting which characters have been inherited from a common ancestor. Students cannot make inferences about the character of taxa from the evolution that occurs, and make conclusions that are not informative, without good interpreting skills (Kummer et al., 2016a).

\section{Monophyletic group}

The second interpretation indicator, namely the monophyletic group, is divided into three indicators. The first sub-indicator is determining the sister group with the acquisition of $72 \%$ which indicates that the students' misreading ability is low and has good mastery of concepts in answering questions with these indicators. Clades or monophyletic group includes all and only the descendants of a particular ancestor. Monophyletic group questions have several indicator items they are to determine sister group, to evaluate relatedness by showing the different form of cladogram, and to determine name of taxon group. Students need to understand about monophyletic group first and they can know where is in the same ancestor and not in same ancestor. 
The second sub-indicator on the ability to evaluate the relationship between taxa in different tree types, obtained a percentage of $0 \%$ which indicates that none of the students were able to answer the question. Students get very high misreading in question number 8 (Figure 2), there is no one can answer it correctly.

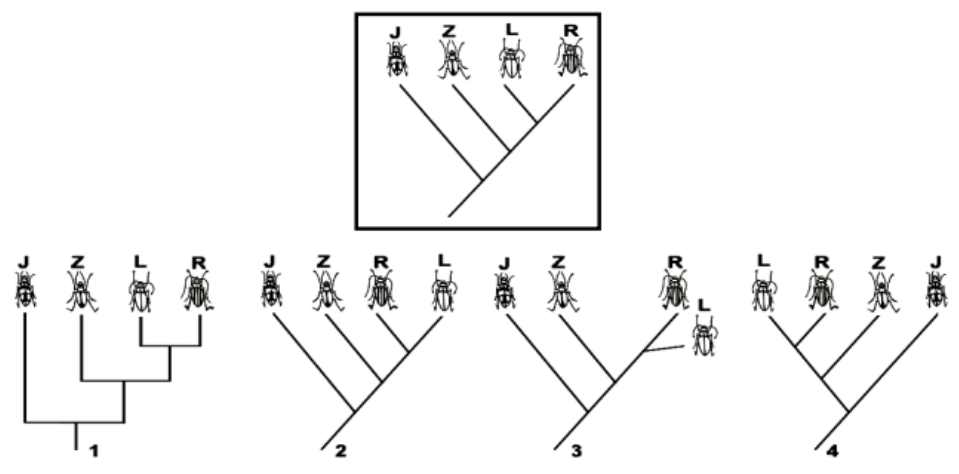

Figure 2. Question number 8

The question number 8 (Figure 2), student must choose figure 1 until 4 that has same meaning with figure in the box. But, no one student be able to choose the right one. They get misreading in position every taxon. Picture in box shows that taxon $L$ and taxon $R$ is in monophyletic group, it has same form with picture number 2 , because only change position between taxon $L$ and taxon $R$ but they are still in the same ancestor. Understanding the concept of a clades is critical to proper interpretation of groups based on evolutionary history. Monophyletic clades are groups that reflect the evolutionary history of the taxa that comprise them, while polyphyletic or paraphyletic groups do not reflect any meaningful history. Being able to identify groups that do and do not reflect evolutionary history allows evolutionary trees to become an important tool for making meaningful classifications of biological diversity (Kummer et al., 2016b). Rotating cladogram branches around their nodes does not change the relationships among the affected taxa, even though the adjacency relations among the taxa do change (Novick \& Catley, 2016).

\section{Branch proximity}

Knowing about relatedness between taxon with another taxon is by seeing branch proximity, if they have short branch proximity it means they have related and maybe same most common recent ancestor and have not long different time. The indicator about branch proximity in questions are consist of determine primitive taxon, determine outgroup, determine last recent taxon, and relatedness taxon based on branch proximity. The third interpretation indicator, namely the proximity of the branch ends, is divided into four sub-indicators. The second sub-indicator, namely identifying outgroups, obtained a percentage of $90 \%$ with a very low misreading category, this shows that students have understood the material about outgroups in the cladogram. Very high misreading occurred in the sub-indicator determining taxon kinship based on the closest branch with a percentage gain of $14.8 \%$. To interpret the question, students need to understand branch proximity to see relatedness each taxon. Students have very low misreading outgroup in cladogram, they can interpret well. It means they understand about outgroup is taxon that has different branch and not in monophyletic group. Students get very high misreading relatedness taxon based on branch proximity, they can not to choose taxon that really has closely related to each other. This is very important, all taxa is emanating from branches that form a polytomy are equally closely related to each other (Novick et al., 2012).

\section{Contemporary descendant}

Question indicators contemporary descendant consists of determine character, character taxon, and character of new species that get from cladogram. Questions are made from number 18-20 that arranged well. Misreading is happening in the second sub-indicator, which is concluding the character of a taxon from the cladogram with a percentage gain of $59 \%$, because only some students answered correctly. The third subindicator is concluding that the character possessed by the new species gets a percentage of $14 \%$ with a very high level of misreading, which shows that many students are wrong in answering questions. If they can read the cladogram well, they can interpret and answer three questions well. Questions can be answer if they understand about MRCA and synapomorphy character. Tree thinking involves not only the technical aspect of reading phylogenies, but also using an overarching understanding of evolution as an emergent biological 
phenomenon and how these diagrams graphically represent the nested hierarchy and descendant from a common ancestor that are the core of evolution research (Gibson \& Hoefnagels, 2015). Systematists recognize the roles of descendant from common ancestry and evolutionary adaptation in establishing patterns of similarity and difference among groups of organisms (Halverson et al., 2011).

\section{Counting the branch or nodes position}

In this indicator, student get high misreading on counting number of clades (38\%) and low misreading on placing taxon in node correctly $(69 \%)$. Understanding about monophyletic group and MRCA can be basic of ability to understand and read cladogram well. Counting number of clades about calculating group which have same character and same MRCA that known as clades. The high misreading rate is affected by the misinterpretation of the branch. This is also found in the research of Halverson et al (2011), Baum et al., (2005) and Gregory (2008), many students who interpret the cladogram are influenced by the branch of the cladogram. Students interpret based on the physical characteristics of the cladogram or phylogenetic tree displayed by looking at the distance between branches and reading the proximity of the ends of the branches. Meanwhile, the low level of misreading in the sub-indicator places a taxon at the cladogram branching point correctly $(69 \%)$. This shows that some students are able to place a taxon at the right node as the correct interpretation of evolutionary relationships between species in the questions asked. Teaching students to process cladograms in a downward direction would presumably help overcome the incorrect strategy of reading across the tips of the cladogram (Gregory, 2008). Another common misinterpretation is that the way to determine evolutionary relatedness is to count the number of steps between the taxa in question. Branches can be rotated about the nodes, however, such that taxa positions are arbitrary (Dees et al., 2014).

Phylogenetic trees are important tools for organizing knowledge of biological diversity, and they communicate hypothesized evolutionary relationships among nested groups of taxa (monophyletic groups) that are supported by shared traits known as synapomorphy. As visualizations, phylogenetic trees are a type of schematic diagram that illustrates abstract concepts rather than appearances of objects (iconic diagrams) or quantitative relationships. Because of this abstract nature, schematic diagrams are used to describe processes that are difficult to observe, such as evolution, and are governed by learned conventions for interpretation (Novick \& Catley, 2014). Sa'adah (2017) showed that students have difficulties in determining character evolution such as synapomorphy and autapomorphy from a phylogenetic tree provided because they do not understand the definition of each character evolution and often confuse one character with another character. The ability to properly read, understand and interpret trees is tree thinking.

Traditionally, MRCA is used to interpret taxa relatedness. Taxa that share a more recent common ancestor must be more closely related to each other than to another taxon with a less recent common ancestor (Dees et al., 2014). Table 2 shows that students' misreading happens in taxa relatedness, they only read cladogram based on distance and position taxon on cladogram. This finding related with Dees et al findings that misinterpreting taxa relatedness is however quite common. The most common misinterpretation related to taxa relatedness is using distance between taxa on phylogenetic trees to determine relatedness, that is, branch tip proximity, often referred to as "reading the tips". Misinterpreting phylogenetic trees is not restricted to errors related to taxa relatedness (Dees et al., 2014). Phylogenetic tree misinterpretations are diverse and pose significant barriers to understanding evolution (Meir et al., 2007). Therefore, we need to improve skill and understanding of students using tree thinking to read and interpret cladogram or phylogenetic tree.

Student errors in reading the cladogram can cause errors in interpretation which are indicated by choosing the wrong answer. In this study, many students misreading cladograms on branches, nodes or branching points, as well as distances between branches so that they misinterpret ancestors, the same descendants, synapomorphy characters in a species, monophyletic group and position species on the cladogram. This is also consistent with the findings of Baum et al (2005) that the proximity of branches is one of the reasons most students interpret the relationship patterns illustrated by the cladogram.

The ability of tree thinking greatly supports students' reading ability of cladogram. The ability of tree thinking in evolutionary learning uses a variety of approaches so that it can help students understand evolution as a phenomenon in biology and provide information about species relatedness, evolutionary timing, species diversity and geographic distribution (Gregory, 2008). Tree thinking also needs to be taught to high school students and biology students. Tree thinking is the ability to interpret, provide reasons, apply information about evolutionary relationships using phylogenetic trees and also reproduce phylogenetic trees with existing biological data and facts (Baum et al., 2005; Gregory, 2008; Halverson et al., 2011). In the 
process of introducing phylogenetic trees, various methods can be used, such as in the research of Bokor et al., (2014) which uses a plant phylogenetic module so that it can increase students' attention and mastery of concepts about plants and also improve students' tree thinking skills using evolution in plants. Gibson and Cooper's research (2017) uses innovative classroom activities related to plant evolution using cards. In the activity, card sorting is carried out based on tree thinking that is tailored to the abilities and experiences of students. Eddy et al (2013) has demonstrated that introducing phylogenies by having students build trees is more effective than having them analyze pre-existing phylogenies. Therefore, the use of tree thinking can be used as an approach to learning evolution, thus honing students' ability to interpret evolutionary relationships through phylogenetic trees. The introduction of phylogenetic trees in evolution to students can be in the form of animal evolution or plant evolution. Novick and Catley (2018)a found in their study that novel laboratory activities gave students the opportunity to use their newly acquired skills to make sense of organismic diversity in terms of evolutionary and ecological relatedness being the products of evolutionary processes.

\section{CONCLUSION}

The results of this study indicate that the misreading analysis of students in reading the cladogram obtained the high category. This shows that most students have a poor ability to interpret phylogenetic trees or have high misreading. The ability of student tree thinking is important to be applied as a link between evolution and other branches of biology. The use of tree thinking in learning activities requires educators (can be done by conducting classroom action research, quasi-experiment, and followed by R\&D to produce certain products/techniques) to be able to apply a tree thinking approach in the process of teaching and learning activities with more emphasis on students to build phylogenetic trees so that they can support students' tree thinking abilities. Using tree thinking in learning can support higher order thinking skills in students and support 21st century skills. Maximizing tree thinking abilities in students can be supported by building phylogenetic trees so that students' tree thinking abilities can be used, and mastery of student concepts regarding phylogenetic trees and tree thinking needs to be improved so that there is no misreading when reading cladograms.

\section{REFERENCES}

Baum, D. A., Smith, S. D. W., \& Donovan, S. S. S. (2005). The tree-thinking challenge. Perspectives, 310(5750), 979-980. https://doi.org/10.1126/science.1117727

Bokor, J. R., Landis, J. B., \& Crippen, K. J. (2014). High school students' learning and perceptions of phylogenetics of flowering plants. CBE Life Sciences Education, 13(4), 653-665. https://doi.org/10.1187 /cbe.14-04-0074

Dees, J., Momsen, J. L., Niemi, J., \& Montplaisir, L. (2014). Student interpretations of phylogenetic trees in an introductory biology course. CBE Life Sciences Education, 13(4), 666-676. https://doi.org/10.1187/cbe 14-01-0003

Dunk, R. D. P., Barnes, M. E., Reiss, M. J., Alters, B., Asghar, A., Carter, B. E., Cotner, S., Glaze, A. L., Hawley, P. H., Jensen, J. L., Mead, L. S., Nadelson, L. S., Nelson, C. E., Pobiner, B., Scott, E. C., Shtulman, A., Sinatra, G. M., Southerland, S. A., Walter, E. M., ... Wiles, J. R. (2019). Evolution education is a complex landscape. Nature Ecology and Evolution, 3(3), 327-329. https://doi.org/10. 1038/s41559-019-0802-9

Eddy, S. L., Crowe, A. J., Wenderoth, M. P., \& Freeman, S. (2013). How should we teach tree-thinking? An experimental test of two hypotheses. Evolution: Education and Outreach, 6(1), 1-11. https://doi.org/10. 1186/1936-6434-6-13

Gibson, J. P., \& Cooper, J. T. (2017). Botanical Phylo-Cards: A tree-thinking game to teach plant evolution. The American Biology Teacher, 79(3), 241-244. https://doi.org/10.1525/abt.2017.79.3.241

Gibson, J. P., \& Hoefnagels, M. H. (2015). Correlations between tree thinking and acceptance of evolution in introductory biology students. Evolution: Education and Outreach, 8(15). https://doi.org/10.1186/s12052015-0042-7

Gregory, T. R. (2008). Understanding evolutionary trees. Evolution: Education and Outreach, 1(2), 121-137. https://doi.org/10.1007/s12052-008-0035-x 
Halverson, Kristy L., Pires, C. J., \& Abell, S. K. (2011). Exploring the complexity of tree thinking expertise in an undergraduate systematics course. Science Education, 95(5), 794-823. https://doi.org/10.1002/ sce. 20436

Halverson, K. L. (2011). Improving tree-thinking one learnable skill at a time. Evolution: Education and Outreach, 4(1), 95-106. https://doi.org/10.1007/s12052-010-0307-0

Hiatt, A., Davis, G. K., Trujillo, C., Terry, M., French, D. P., Price, R. M., \& Perez, K. E. (2013). Getting to evodevo: Concepts and challenges for students learning evolutionary developmental biology. CBE Life Sciences Education, 12(3), 494-508. https://doi.org/10.1187/cbe.12-11-0203

Hidayat, T., \& Pancoro, A. (2016). Kajian filogenetika molekuler dan peranannya dalam menyediakan informasi dasar untuk meningkatkan kualitas sumber genetik anggrek. Jurnal AgroBiogen, 4(1), 35. https://doi.org/10.21082/jbio.v4n1.2008.p35-40

Klucevsek, K. M., \& Brungard, A. B. (2016). Information literacy in science writing: how students find, identify, and use scientific literature. International Journal of Science Education, 38(17), 2573-2595. https:// doi.org/10.1080/09500693.2016.1253120

Kummer, T. A., Whipple, C. J., \& Jensen, J. L. (2016a). Prevalence and persistence of misconceptions in tree thinking. Journal of Microbiology \& Biology Education, 17(3), 389-398. https://doi.org/10.1128/jmbe. v17i3.1156

Kummer, T. A., Whipple, C. J., \& Jensen, J. L. (2016b). Prevalence and persistence of misconceptions in tree thinking. Journal of Microbiology \& Biology Education, 17(3), 389-398. https://doi.org/10.1128/jmbe. v17i3.1156

Mattsson, J.-E., \& Mutvei, A. (2015). How to teach evolution. Procedia - Social and Behavioral Sciences, 167, 170-177. https://doi.org/10.1016/j.sbspro.2014.12.658

McCullough, E. L., Verdeflor, L., Weinsztok, A., Wiles, J. R., \& Dorus, S. (2020). Exploratory activities for understanding evolutionary relationships depicted by phylogenetic trees: United but diverse. American Biology Teacher, 82(5), 333-337. https://doi.org/10.1525/abt.2020.82.5.333

Meir, E., Perry, J., Herron, J. C., \& Kingsolver, J. (2007). College students' misconceptions about evolutionary trees. The Ameri, 549-550. https://doi.org/10.1016/B978-0-12-374984-0.00504-0

Meisel, R. P. (2010). Teaching tree-thinking to undergraduate biology students. Evolution: Education and Outreach, 3(4), 621-628. https://doi.org/10.1007/s12052-010-0254-9

Morrison, D. A. (2012). Tree Thinking: An introduction to phylogenetic biology. David A. Baum and Stacey D. Smith. In Systematic Biology. https://doi.org/10.1093/sysbio/syt026

Novick, L. R., \& Catley, K. M. (2007). Understanding phylogenies in biology: The Influence of a gestalt perceptual principle. Journal of Experimental Psychology: Applied. https://doi.org/10.1037/1076898X.13.4.197

Novick, L. R., \& Catley, K. M. (2014). When relationships depicted diagrammatically conflict with prior knowledge: An investigation of students' interpretations of evolutionary trees. Science Education, 98(2), 269-304. https://doi.org/10.1002/sce.21097

Novick, L. R., \& Catley, K. M. (2016). Fostering 21st-Century evolutionary reasoning: Teaching tree thinking to introductory biology students. CBE Life Sciences Education, 15(4), 1-12. https://doi.org/10.1187/cbe. 15-06-0127

Novick, L. R., \& Catley, K. M. (2018). Teaching tree thinking in an upper level organismal biology course: Testing the effectiveness of a multifaceted curriculum. Journal of Biological Education, 52(1), 66-78. https://doi.org/10.1080/00219266.2017.1285804

Novick, L. R., Stull, A. T., \& Catley, K. M. (2012). Reading phylogenetic trees: The effects of tree orientation and text processing on comprehension. BioScience, 62(8), 757-764. https://doi.org/10.1525/bio. 2012.62.8.8

Padian, K. (2008). Trickle-down evolution: An approach to getting major evolutionary adaptive changes into textbooks and curricula. Integrative and Comparative Biology, 48(2), 175-188. https://doi.org/10. 1093/icb/icn023

Phillips, B. C., Novick, L. R., Catley, K. M., \& Funk, D. J. (2012). Teaching tree thinking to college students: It's not as easy as you think. Evolution: Education and Outreach, 5(4), 595-602. https://doi.org/10.1007/s12052-012-0455-5

Sa'adah, F. (2017). Undergraduate students' initial ability in understanding phylogenetic tree. Journal of Physics: Conference Series, 824(1), 1-5. https://doi.org/10.1088/1742-6596/755/1/011001 
Saputra, A. (2017). Persepsi mahasiswa calon guru biologi tentang pembelajaran materi evolusi di SMA: Studi kasus mahasiswa Pendidikan Biologi FKIP Universitas Sebelas Maret Surakarta. Bioeducation Journal, 1(1), 1-9. http://ejournal.unp.ac.id/index.php/bioeducation/article/view/7085

Schramm, T., Jose, A., \& Schmiemann, P. (2021). Seeing the woods for the trees again: Analyzing evolutionary diagrams in German and US university-level textbooks. Education Sciences, 11. https:// doi.org/10.3390/educsci11080367

Whitfield, J. B. (2012). Phylogenetic networks: Concepts, algorithms and applications. In Systematic Biology (Vol. 61, Issue 1). https://doi.org/10.1093/sysbio/syr055 